\title{
Educação inclusiva no ensino remoto emergencial
}

\author{
Inclusive education in emergency online learning \\ Educación inclusiva en clases remotas de emergencia
}

Recebido: 09/01/2022 | Revisado: 13/01/2022 | Aceito: 19/01/2022 | Publicado: 22/01/2022

\author{
Márcio Jean Fernandes Tavares \\ ORCID: https://orcid.org/0000-0002-9318-6099 \\ Instituto Federal de Educação, Ciência e Tecnologia da Paraíba, Brasil \\ E-mail: marcio.jean@academico.ifpb.edu.br \\ Júlia Maria Soares Ferraz \\ ORCID: https://orcid.org/0000-0003-2769-6864 \\ Instituto Federal de Educação, Ciência e Tecnologia da Paraíba, Brasil \\ E-mail: julia.ferraz@academico.ifpb.edu.br \\ Niely Silva de Souza \\ ORCID: https://orcid.org/0000-0003-4067-6104 \\ Instituto Federal de Educação, Ciência e Tecnologia da Paraíba, Brasil \\ E-mail: niely@ifpb.edu.br \\ Alessandra Marcone Tavares Alves de Figueirêdo \\ ORCID: https://orcid.org/0000-0001-6611-4797 \\ Instituto Federal de Educação, Ciência e Tecnologia da Paraíba, Brasil \\ E-mail: alessandratavaresfigueiredo@ifpb.edu.br \\ Carlos Alberto da Silva Júnior \\ ORCID: https://orcid.org/ 0000-0002-1118-359X \\ Instituto Federal de Educação, Ciência e Tecnologia da Paraíba, Brasil \\ E-mail: carlos.alberto@ifpb.edu.br
}

\begin{abstract}
Resumo
A pandemia do novo coronavírus intensificou diversas problemáticas educacionais e, com isso, o Ensino Remoto Emergencial surgiu como uma alternativa para a resolução desses impasses. Contudo, essa estratégia contribuiu para a construção de diversas barreiras de ensino, entre elas, se destaca a carência na promoção de métodos voltados aos princípios de uma Educação Inclusiva para todos. Assim, o presente artigo teve como objetivo a aplicação de um software que facilita a visualização do Tradutor Intérprete da Língua de Sinais (TILS), sendo aquele um recurso que evita o excesso de informação visual e permite a exibição simultânea do TILS com o material de aula apresentado. O processo metodológico teve um perfil qualitativo que passou pela validação de um estudante surdo, apresentando resultados satisfatórios, indicando a importância da ampliação da inclusão no trabalho docente, tal como a necessidade de incentivos ao avanço de estudos nesta importante área que muitas vezes é esquecida.
\end{abstract}

Palavras-chave: Educação inclusiva; Ensino remoto emergencial; Acessibilidade; TDICs.

\begin{abstract}
The pandemic of the new coronavirus intensified several educational problems and Emergency Online learning emerged as an alternative to some of those nowadays impasses. However, this strategy contributed to the construction of several teaching barriers, among them, we highlight the lack of promotion of methods focused on the principles of an Inclusive Education for everyone. This article in bringing measures of accessory through the use of a software that facilitates the visualization of the Sign Language Interpreting Professional (SLIP), which is a resource that avoids excessive visual information and allows the simultaneous display of SLIP with the presented lesson material. The methodological process had a qualitative approach that went through a deaf student validation, presenting satisfactory results and indicating the importance of expanding inclusion in teaching labour, as well as the need for incentives to advance studies in this relevant area that is often forgotten.
\end{abstract}

Keywords: Inclusive education; Emergency online learning; Accessibility; DICTs.

\section{Resumen}

Con la nueva pandemia de coronavirus fueron criados muchos recursos de emergencia en todas los médicos sociales, económicos y educativos. Por lo tanto, este artículo tiene como objetivo aplicar un software que facilite la visualización del Traductor Intérprete de Lengua de Signos (TILS), que es un recurso que evita el exceso de información visual y permite la visualización simultánea del TILS con el material de clase presentado. Pues, en la parte Educativa fueron elaboradas un plan de Clases Remotas de Emergencia con el objetivo de llevar a educación adelante. Sin embargo, esta estrategia contribuyó a la construcción de varias barreras docentes, entre ellas se destaca la falta de promoción de métodos orientados a los principios de una Educación Inclusiva para todos, principalmente 
de alumnos sordos. El proceso metodológico con tuvo un perfil cualitativo que pasó por la validación de un alumno sordo, con resultados satisfactorios e indicando la importancia de ampliar la inclusión en la labor docente, así como la necesidad de incentivos para avanzar en los estudios en esta importante área que a menudo se olvida.

Palabras clave: Educación inclusiva; Educación en línea temporal; Accesibilidad; TDICs.

\section{Introdução}

A educação escolar de surdos passou por diversas modificações ao longo do tempo, visto que de acordo com Glat e Ferreira (2003) ocorreram inúmeros episódios de segregação e discriminação junto às Pessoas com Deficiência (PcD), especialmente a Comunidade Surda (CS). Vieira e Molina (2018) indicam que, por muito tempo, a CS foi obrigada a se privar da comunicação por intermédio da Língua de Sinais, devido a implementação do oralismo para "normalizar" esses indivíduos. Perlin e Strobel (2006) discorrem sobre o movimento oralista, apontando-o como responsável por causar consideráveis danos na vida de muitos surdos:

Nenhum outro evento na história de surdos teve um impacto maior na educação de povos surdos como este que provocou uma turbulência séria na educação que arrasou por mais de cem anos nos quais os sujeitos surdos ficaram subjugados às práticas ouvintistas, tendo que abandonar sua cultura, a sua identidade surda e se submeteram a uma "etnocêntrica ouvintista", tendo de imitá-los (p. 11).

Os debates relativos à presença das PcD nas escolas de forma efetiva só tiveram início a partir da Promulgação da Declaração de Salamanca (1994) e a educação passou a ser vislumbrada como fator indissociável ao processo de inclusão (BRASIL, 1994). No Brasil, como demonstram Mendes e Reis (2021), os primeiros discursos a respeito da inclusão escolar foram resultantes da Lei de Diretrizes e Bases da Educação Nacional (LDB) n 9.394/1996, tal legislação indicou a necessidade de adaptação e adequação das escolas brasileiras e, das metodologias e materiais didáticos empregados nesses espaços, com objetivo de atender satisfatoriamente a todos os estudantes.

Em contrapartida, conforme descreve Trevisan (2019), apesar do ensino inclusivo se apresentar como uma alternativa viável para o setor educacional, muitas vezes esse tipo de ensino é interpretado pelas Instituições Escolares (IEs) de forma equivocada, não havendo devida atenção para uma adaptação estrutural de todo setor que garanta aos discentes uma assistência de forma legítima, dessa maneira, o autor indica que o processo inclusivo acaba sendo aplicado de forma errada se aproximando mais de um procedimento de "integração" escolar, do que de "inclusão" escolar, a Figura 1 ilustra tal diferença.

Figura 1: Diferença entre a Integração e a Inclusão.

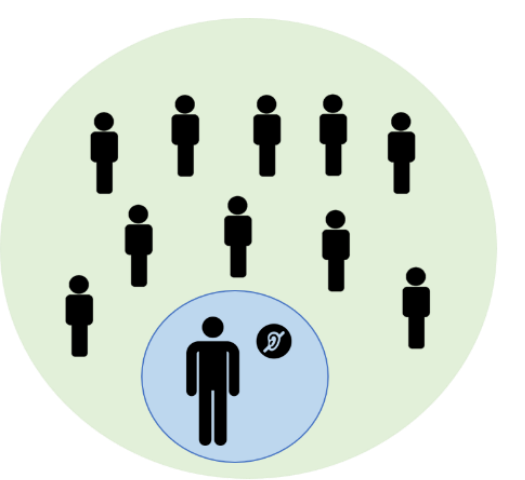

Integração

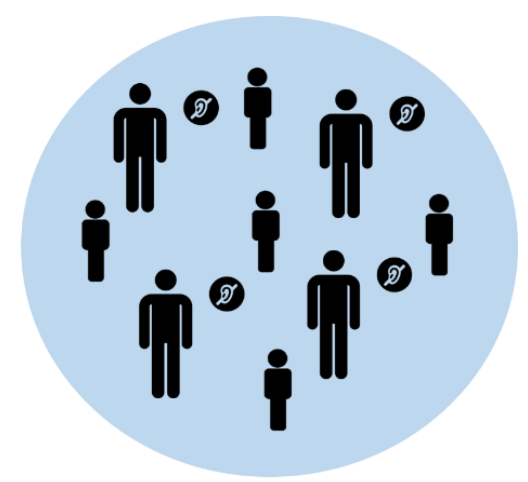

Inclusão

Fonte: Autoria própria (2021). 
Em consequência disso, a escola inclusiva acaba sendo preconizada pela Comunidade Surda, entretanto, na vivência prática desses espaços os alunos surdos adquirem o papel de adaptação à escola, o que resulta em vários pontos negativos, como o isolamento do discente surdo em relação aos ouvintes, gerando dificuldades no processo de ensino e aprendizagem. Assim, a inclusão toma um perfil de exclusão e, por isso a CS defende a escola bilíngue, pois ela é totalmente planejada e desenvolvida para o discente surdo (IsFlocos, 2017; ViSurdo, 2018). É válido lembrar que, para que ocorra uma inclusão eficaz, a escola é que deve se adaptar às necessidades das PcD.

Nesse sentido, entende-se a necessidade de uma modificação da prática que vem sendo empregada nas escolas, visando atender aos princípios teóricos do paradigma inclusivo. A vivência bilíngue deveria estar nas escolas inclusivas, $\log$ o a capacitação docente em relação à Língua de Sinais é fundamental, para que em parceria com os Tradutores Intérpretes da Língua de Sinais (TILS), haja interação entre professores e alunos. Assim, a comunicação não dependerá exclusivamente da tradução, dado que esse é um fator que funciona como uma das barreiras de aprendizagem existentes nas escolas inclusivas (IsFlocos, 2017; ViSurdo, 2018). Ações como essa garantem e promovem o protagonismo do aluno surdo, o que é de grande importância para o processo de desenvolvimento desses discentes (Maciel-Ferreira, 2021).

Analisando os desafios apontados sobre a ampliação de metodologias, bem como ações e modificações estruturais nas escolas, Oliveira, Pinto de Oliveira e Barbosa (2021) assinalam tais dificuldades como sendo aspectos que vêm se fortalecendo na crise sanitária mundial causada pela Covid-19, visto que é perceptível "a falta de ação por parte dos órgãos governamentais para uma inclusão de fato no atual cenário vivido" (p. 6).

Em concernência ao contexto de pandemia, pesquisas apontam que a temática supracitada se tornou um dos assuntos mais pesquisados no período vigente (Amaral, 2020), de modo que essas buscas possuem principal enfoque nos impactos causados pelo vírus na sociedade que, resultaram em significativas modificações e/ou adaptações nas grandes esferas mundiais econômicas e sociais. Tais impactos trouxeram como eixo principal um caráter de vulnerabilidade global que, de acordo com Sousa (2020) não se resume apenas a uma questão de saúde, mas principalmente a uma questão da construção de barreiras de acesso, condicionando a um violento processo de exclusão.

Dessa forma, o Ensino Remoto Emergencial (ERE) surge como uma alternativa com natureza de urgência para a resolução das problemáticas estabelecidas ao setor educacional nesse atual cenário caótico, tornando possível a continuidade das aulas por intermédio das Tecnologias Digitais de Informação e Comunicação (TIDCs). É importante salientar que o ERE não deve ser entendido como o sistema de Ensino a Distância (EAD), visto que o último se trata de uma modalidade bem definida, estruturada e planejada e, não algo acidental ou emergencial (Coqueiro \& Sousa, 2020).

O ensino remoto nos tempos de pandemia se caracteriza como uma solução repentina para continuidade das aulas em todos os níveis de ensino. Entretanto, Ferreira et al. (2020) discorrem que essa "estratégia" intensificou diversas problemáticas no sistema educacional, tais como o fortalecimento da já existente precarização do ofício docente, por meio do aumento na carga horária de trabalho e das despesas para os trabalhadores em home office.

Os referidos autores citam também a redução da interação entre professores e alunos com a implementação do ERE, como um dos impasses que prejudicou consideravelmente o sistema de ensino de muitas escolas. De acordo com a Nota Técnica "Ensino a distância na Educação Básica frente à pandemia da Covid-19", esse contratempo pode ser entendido como um fator decorrente da tímida presença de usabilidade das tecnologias no ensino presencial (Brasil, 2020), muitas vezes, pela falta de incentivos financeiros e da escassez de recursos.

No ensino remoto, assim como na modalidade EAD o andamento das aulas síncronas e assíncronas se dispõe dos Ambientes Virtuais de Aprendizagem (AVAs), que são ferramentas de mídia tecnológica com a finalidade de potencializar o sistema de ensino não presencial (Pereira et al., 2007). Esses recursos possuem o papel de promover uma mediação entre educadores e educandos durante os encontros remotos, todavia, existem diversas limitações nos AVAs em relação a 
acessibilidade para todos os alunos (Garbado et al., 2010).

Além dos desafios da falta de uma efetiva inclusão na vivência escolar, a CS tem sido prejudicada ainda pelos impactos da carência de acessibilidade decorrentes do distanciamento social na educação. Essa condição, pode ser explicada devido ao despreparo de muitos professores em relação ao trabalho inclusivo, mesmo essa sendo uma tarefa indispensável para toda a comunidade escolar (Bersch, 2008). Existe também nessa perspectiva, um desconhecimento quanto ao conceito do termo "Acessibilidade" que, segundo Silva et al. (2021) é entendido de acordo com a Lei Brasileira de Inclusão (LBI) da Pessoa com Deficiência (2015), como sendo:

possibilidade e condição de alcance, percepção e entendimento para utilização, com segurança e autonomia, de espaços, mobiliários, equipamentos urbanos, edificações, transportes, informação e comunicação, inclusive seus sistemas e tecnologias, bem como outros serviços e instalações abertos ao público, de uso público ou privado de uso coletivo, tanto na zona urbana como na rural, por pessoa com deficiência ou com mobilidade reduzida (Brasil, 2015).

Silva et al. (2021) expõem o conceito da acessibilidade - citando Sassaki (2004) - em seis dimensões, sublinhando que o estudo do mencionado tema precisa ser integrado aos conteúdos programáticos de todos os níveis de ensino. A Figura 2, baseada nos dados da pesquisa de Silva et al. (2021) em referência a acessibilidade educacional de acordo com Sassaki (2004), indica essas diferentes concepções.

Figura 2: Dimensões da Acessibilidade na Educação.

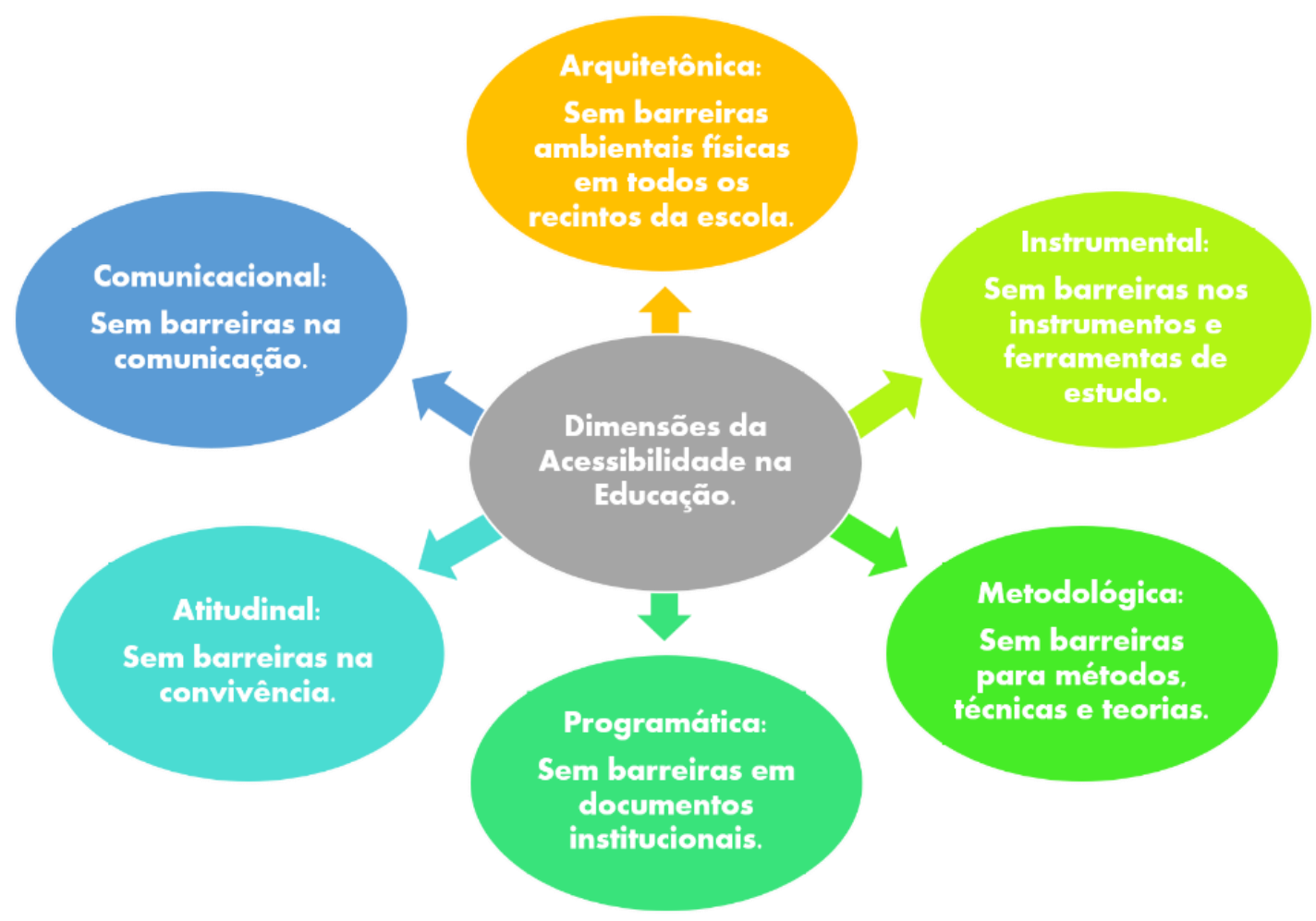

Fonte: Própria (2021) - Adaptado de Silva et al. (2021) e Sassaki (2004).

Deste modo, entende-se a fundamental importância da promoção de metodologias acessíveis para garantia de um processo inclusivo de forma concreta, visto que como citam Silva et al. (2021) a Lei Brasileira de Inclusão da Pessoa com Deficiência, estabelece em seu art. $4^{\circ}$ que toda pessoa com deficiência tem direito a igualdade de oportunidades tal qual aos demais indivíduos, sem discriminações em razão de sua condição (Brasil, 2015). Assim, tomando também como base o fato de 
que a educação é um direito constitucional para todos, logo se justifica a necessidade da uma ação escolar inclusiva em qualquer modalidade de ensino, especialmente no ERE, que atenda aos discentes e suas particularidades, sem exceção.

Para isso, é necessário que os docentes tenham conhecimento sobre estratégias para a intensificação da aprendizagem da CS, por intermédio da utilização dos chamados 'Artefatos Culturais' que compõem a comunidade. Strobel (2008) cita três desses artefatos, são esses: o primeiro artefato é a experiência visual que se apresenta como o método pelo qual o alusivo público adquire conhecimento, desenvolvimento e lazer, além de ser um meio que garante comunicação, ou seja, para o sujeito surdo essa experiência promove segurança, funcionando como um canal de acesso ao mundo.

$\mathrm{O}$ segundo artefato, de acordo com a autora, diz respeito ao aspecto linguístico, que se relaciona diretamente à Língua de Sinais, podendo ser considerado como uma porta que abre acesso à informação e ao conhecimento, sendo este um fator indispensável na vivência de tais indivíduos, visto que é por meio dele que os mesmos exercem seus desejos e vontades, apresentam seus questionamentos sobre a vida e se comunicam com outras pessoas, quebrando barreiras atitudinais que foram estabelecidas ao longo dos anos.

Por fim, Strobel (2008) cita a literatura surda como o último artefato fundamental para a comunidade, indicando-a como um método que possibilita a inserção de ouvintes no universo da CS, esse artefato além de servir como um aspecto que amplia a cultura e agrega uma maior relevância, também funciona como um objeto fomentador da educação para potenciais membros da comunidade. Assim, a autora indica que a ampliação de tais artefatos dentro do universo educacional, expandem a Cultura Surda e, com esse desenvolvimento a CS passa cada vez mais a construir seus ideais, suas metas e suas subjetividades para atender de forma efetiva ao desenho universal, tornando o universo escolar verdadeiramente inclusivo.

Dentro desse contexto, o presente artigo se justifica na exposição de uma janela de oportunidades para sanar as problemáticas de inclusão para discentes surdos no Ensino Remoto Emergencial, trazendo medidas de acessibilidade educacional por meio da utilização das TDICs, objetivando a aplicação de um software que facilita a visualização do Tradutor Intérprete da Língua de Sinais pelo aluno surdo nas aulas online.

\section{Metodologia}

O presente artigo foi desenvolvido e aplicado no Instituto Federal de Educação, Ciência e Tecnologia da Paraíba (IFPB) - Campus João Pessoa, Brasil, aspirando a aprovação metodológica por um discente surdo, tendo como base a metodologia de cunho qualitativo e participante. A qualitativa segundo Weller e Pfaff (2011), almeja "a compreensão de questões educacionais vinculadas a preconceitos sociais e sociocognitivos de diversas naturezas", principalmente no contexto complexo da educação inclusiva, já a metodologia participante, incentiva a interação entre investigador e o meio, visando coletar modos de vida sistemáticos, diretamente do contexto ou situação específica da comunidade (Marconi \& Lakatos, 2021).

A aplicação do trabalho deu-se em um rito metodológico de três momentos, conforme pode ser visualizado na Tabela $1:$

\begin{tabular}{|l|c|}
\hline $\mathbf{1}^{\mathbf{0}}$ Momento & $\begin{array}{c}\text { Tabela 1: Rito metodológico } \\
\text { Identificação do problema realizada com o auxílio dos TILS (com a realização de } \\
\text { duas perguntas chaves: 1- Como os professores realizam a apresentação da tela } \\
\text { do intérprete e do recurso visual? 2- Possui alguma adaptação ou preparo } \\
\text { específico de materiais visuais para o discente surdo? }\end{array}$ \\
\hline $\mathbf{2}^{\mathbf{0}}$ Momento & \begin{tabular}{c} 
Levantamento de possíveis soluções em conjunto com os TILS. \\
\hline $\mathbf{3}^{\circ}$ Momento
\end{tabular} \\
\hline
\end{tabular}

Fonte: Autoria própria. 
Vale ressaltar que todo processo de aplicação se deu de forma remota, tendo em vista a suspensão das aulas presenciais, devido à pandemia do Covid-19, atendendo as recomendações da Organização Mundial de Saúde (OMS) seguindo a Resolução 29/2020 - CONSUPER/DAAOC/REITORIA/IFPB (IFPB, 2020).

\section{Resultados e Discussão}

\section{1 $1^{\circ}$ Momento - Identificação do problema realizada com o auxílio dos TILS.}

Durante o primeiro momento de aplicação foi realizado um apanhado do histórico das aulas no ensino remoto no IFPB, juntamente com os TILS, com base na metodologia utilizada por professores de salas inclusivas na qual o discente surdo participava, as perguntas chaves para a identificação do problema foi realizada com o levantamento de duas questões:

I. Como os professores realizam a apresentação da tela do intérprete e do recurso visual?

II. Possui alguma adaptação ou preparo específico de materiais visuais para o discente surdo?

As respostas obtidas foram catastróficas, como podem ser observadas nos itens 3.1.1 e 3.1.2.

\subsubsection{Análise da primeira questão.}

Para a primeira questão a resposta foi negativa, os intérpretes afirmaram que a apresentação da tela era realizada de maneira improvisada (de qualquer maneira), com a repartição da tela inteira em duas partes, prejudicando a visualização tanto do recurso visual utilizado, como do intérprete, conforme pode ser constatado nas Figuras 3 e 4:

Figura 3: Primeira versão da metodologia defasada utilizada por professores.

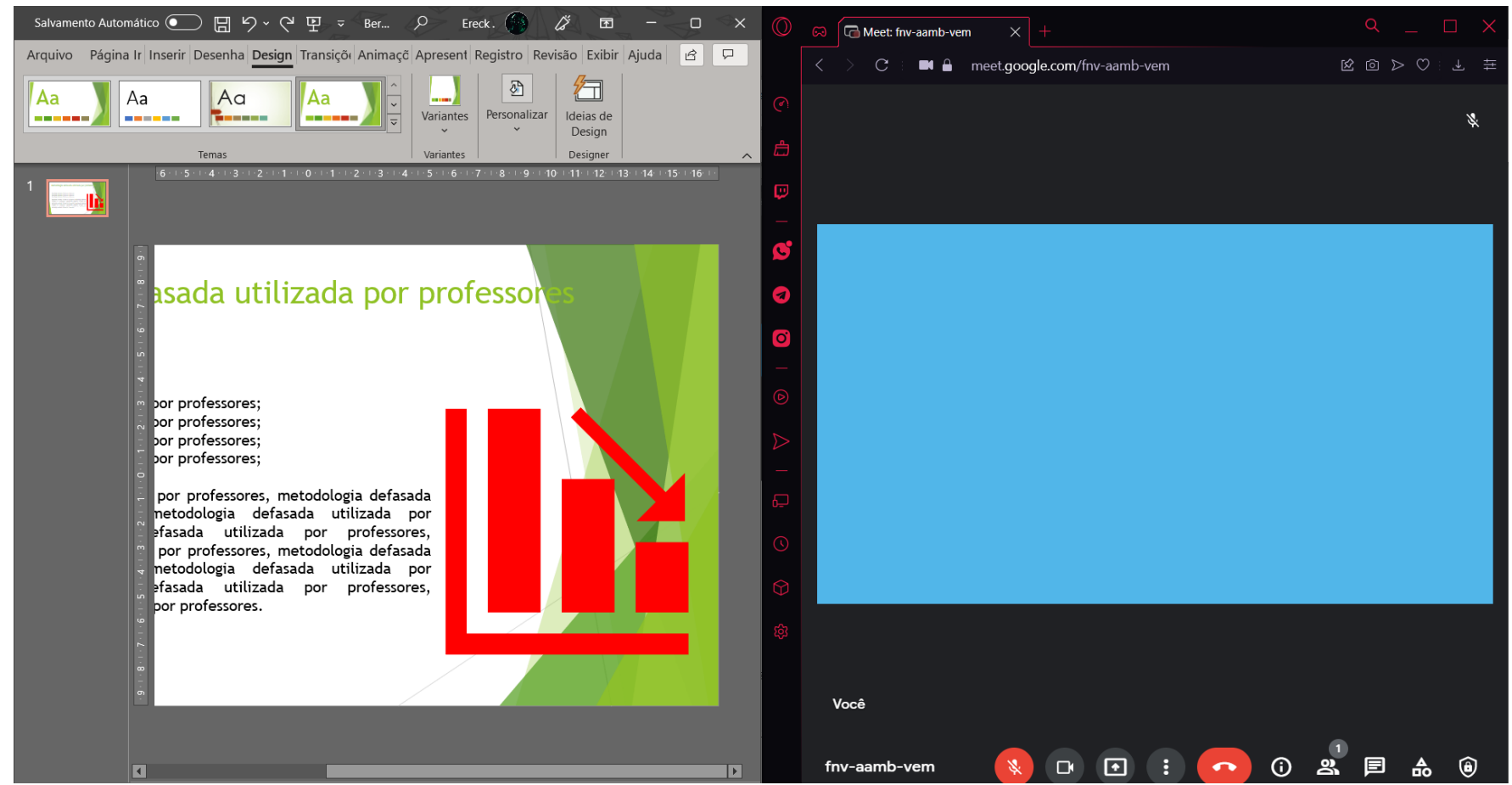

Fonte: Autoria própria. 
Figura 4: Segunda versão da metodologia defasada utilizada por professores.

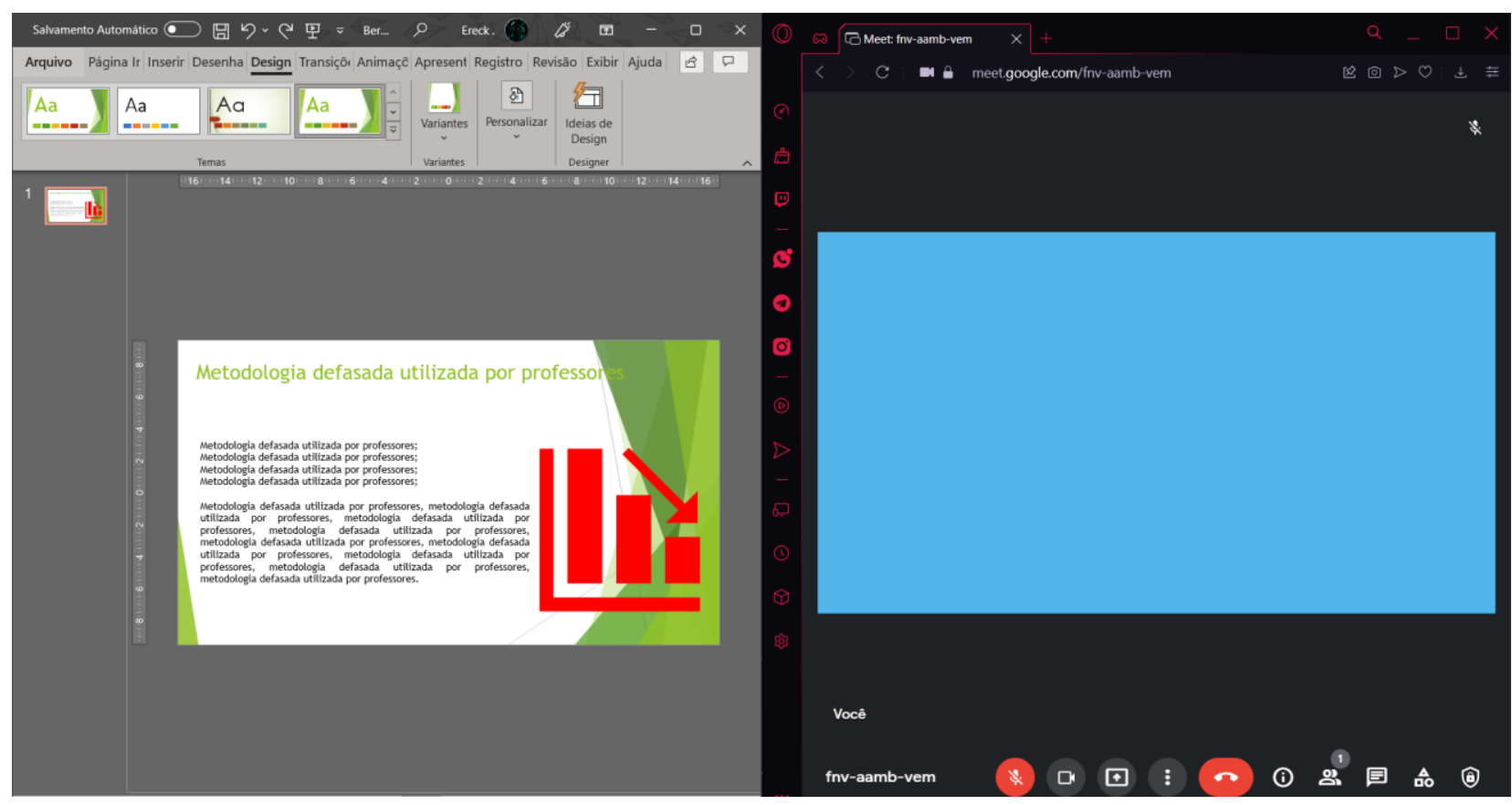

Fonte: Autoria própria.

Como pode ser observado nas Figuras 3 e 4, os alunos surdos são prejudicados com a má utilização dos recursos visuais (RV), as imagens apresentadas, lamentavelmente, representam a realidade de uma sala de aula supostamente inclusiva. Nessas citadas Figuras constatamos que a visualização dos intérpretes é prejudicada, assim como a viabilidade do recurso visual é colocado em "check", uma vez que para uma absorção adequada, faz-se necessária a criação de recursos específicos para uma sala inclusiva composta por discentes surdos, sem medidas provisórias.

$\mathrm{Na}$ Figura 3, percebemos que uma margem de $30 \%$ a $40 \%$ do recurso visual utilizado é perdida, invalidando esta ferramenta de inclusão, prejudicando todos os participantes do processo de ensino e aprendizagem. Já na Figura 4, nota-se a apresentação inteira do recurso visual, mas nota-se uma ênfase maior do uso excessivo de textos e o conflito da imagem com o layout de apresentação gerando uma poluição visual, prejudicando assim, todos os envolvidos na busca do saber efetivo. Ainda podemos constatar em ambas as figuras, a falta de contraste entre o título e o layout, situação que se faz recorrente em todos os níveis de ensino. Vale frisar que as figuras representam a realidade encontrada durante a aplicação deste trabalho, por questões éticas, as imagens foram reconstituídas prezando pelo sigilo da identidade do autor original dos slides.

Percebe-se que essa situação caótica do uso incorreto da ferramenta visual agrava-se primordialmente no atual Ensino Remoto Emergencial, que segundo Kubrusly (2021), gera um grande afastamento educacional, ocasionando uma sobrecarga e fadiga cognitiva nos discentes, sobretudo, devido ao uso quase exclusivo do celular para acompanharem as aulas, esta também era a situação do discente surdo. Além disso, a poluição visual proporciona o "zoom fatigue" que segundo Rump e Brand docentes do Institut für Beschäftigung und Employability (IBE) (2020) e Bailenson (2021), é caracterizado pela fadiga causada após longas chamadas de vídeo, causando uma situação mais delicada.

Diante do ponto de vista inclusivo, essa metodologia defasada de exibição do intérprete de modo "simultâneo" com a ferramenta visual é prejudicial, tanto para surdos como para ouvintes, a extrema poluição visual é ressaltada de modo enfático, reduzindo a atenção e validade da TDICs. Diante de tais afirmações, é de suma importância levantar o seguinte questionamento: "Mas é tão importante assim a boa qualidade destes Recursos Visuais?", Strobel (2008), aponta que a visualidade para o surdo é fundamental, visto que com a ausência da audição os surdos distinguem o mundo que os cercam 
valendo-se dos seus olhos como mediadores, desde o simples latido de um cachorro, percebido pelo movimento bucal e as expressões de rigidez facial e corporal, até a detonação de explosivos, constatados com a queda abrupta de objetos, a fumaça e o clarão da explosão. Destacado esse enorme valor da visualidade, torna-se imprescindível a produção de recursos visuais de qualidade para esta comunidade.

\subsubsection{Análise da segunda questão.}

Em menção a segunda questão: "Possui alguma adaptação ou preparo específico de materiais visuais para o discente surdo?” Os Tradutores Intérpretes da Língua de Sinais afirmaram que não possuía nenhuma adaptação ou preparo específico de materiais para suprir a necessidade do discente surdo, sendo este prejudicado, segregado do processo de ensino e aprendizagem, possuindo exclusivamente o aproveitamento da tradução do TILS, mesmo que em um ambiente de aprendizagem altamente poluído visualmente. Ainda foi destacado de modo tímido que os TILS não participavam do processo de confecção das TDICs utilizadas, o que agrava ainda mais a situação, visto que com o material entregue previamente, os intérpretes podem realizar uma melhor adaptação da linguagem para os discentes surdos.

As respostas dos dois questionamentos levantados demonstram a situação complexa encontrada, um aluno surdo sem uma boa adaptação do conteúdo para a LIBRAS, devido a não participação dos TILS no processo de confecção dos Recursos Visuais, nem o recebimento prévio dos slides utilizados em aula, tais fatores ainda somados com a problemática da sobrecarga visual encontrada, dificultam a aprendizagem.

\section{$3.22^{\circ}$ Momento - Levantamento de possíveis soluções em conjunto com os TILS.}

Quadros (1997), afirma que os recursos visuais, didáticos e documentais devem envolver a visualidade, já que esta é de suma importância para comunidade surda (Strobel, 2008). Diante disto, foi realizada uma profunda busca para acabar com as dificuldades encontradas com as respostas obtidas no item 3.1 deste trabalho. A solução mais simples foi no tocante a sanar a poluição visual, com o preparo do RV de modo limpo, apenas com informações de grande valia, evitando o uso de letras em fontes pequenas ou de difícil compreensão, a exemplo da Figura 5:

Figura 5: Solução para reduzir a poluição visual do RV.

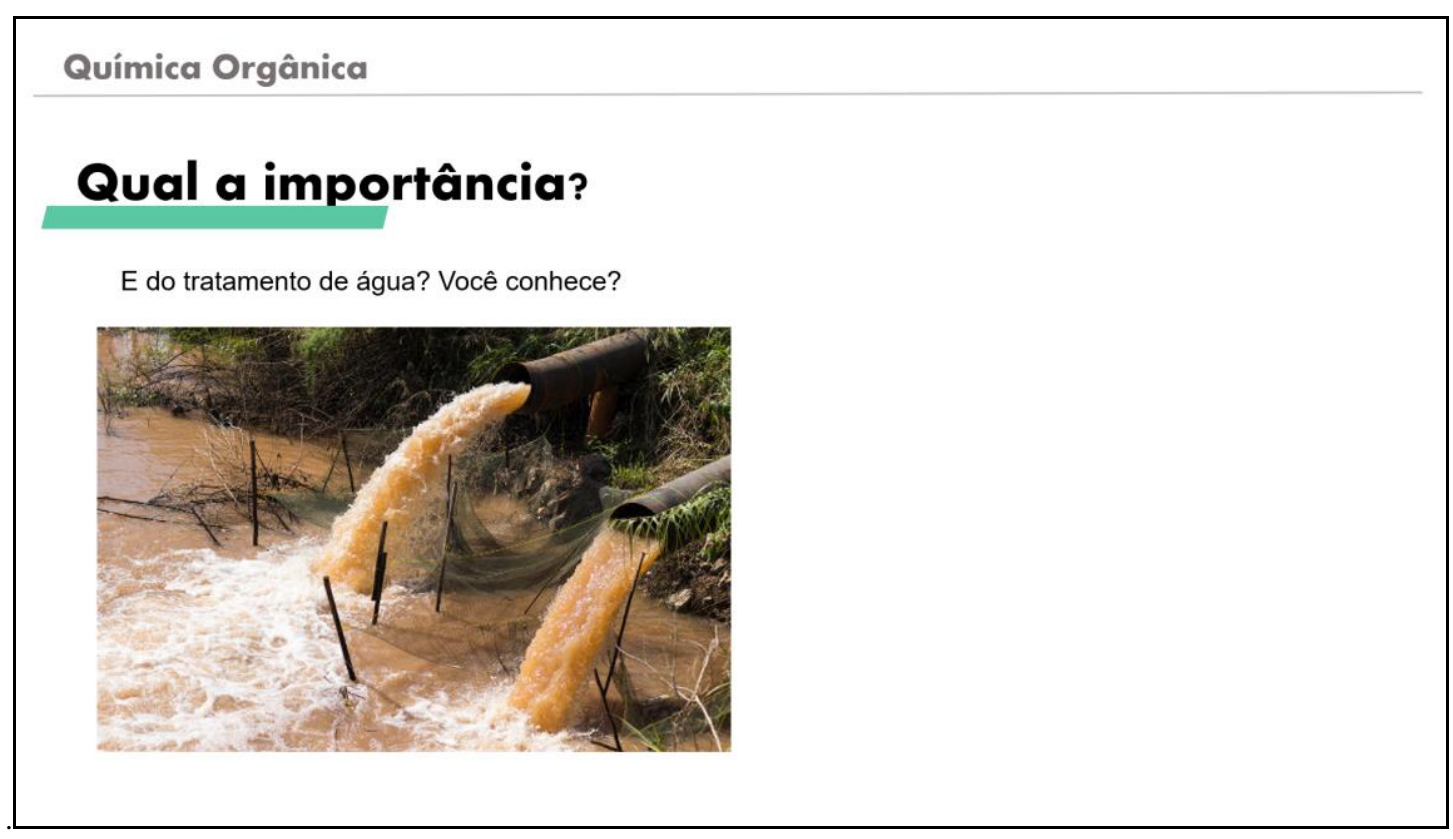

Fonte: Autoria própria. 
Como pode ser analisado na Figura 5, não há poluição visual, nem mesmo excesso de palavras, existe o realce de informações ou questionamentos importantes para a aula que viria a ser ministrada posteriormente, outrossim, a imagem utilizada é de ótima qualidade. No que tange ao vasto espaço em branco do lado direito, tal espaço foi dedicado a solução para a real visualização simultânea do TILS e do Recurso Visual, este ponto será abordado de modo mais aprofundado mais na frente.

Após solucionada a primeira problemática, foi iniciado o processo de resolução de: "Como ofertar a visualização realmente simultânea do TILS com o RV?”, este questionamento foi quase impossível de ser solucionado, não havia artigos, matérias, ou ferramentas dos sites de videochamadas (principalmente o utilizado pelo IFPB, o "Google Meet") que fornecessem esta informação. A busca foi sanada após um integrante do projeto lembrar que possuía um software de duplicação de tela, software este desconhecido por grande parte dos pesquisadores e professores, o referido software é o "OnTopReplica" (OnTopReplica, 2017), este replica uma parte selecionada da tela ou janela simultaneamente, com a apresentação de slide, por exemplo, por meio da execução em segundo plano. Desta maneira, foi possível solucionar tal dificuldade, proporcionando ao TILS um espaço dedicado na janela de apresentação, em paralelo com a reprodução das TDICs. Lamentavelmente, esse software teve seu site oficial retirado do ar, porém, podendo ter seu instalador baixado com o Link 1:

Link 1: Link para o download do software "OnTopReplica”. https://drive.google.com/drive/folders/19Ew6fkkXhu4QGzjOByIKSmbQPoJZMIFn?usp=sharing

Fonte: Autoria própria.

O software é de fácil uso e intuitivo e, mesmo assim, é desconhecido por grande parte do nicho citado. As Figuras 6 a 9 ilustram um tutorial de como utilizar tal software:

Figura 6: Parte um do tutorial de uso do "OnTopReplica".

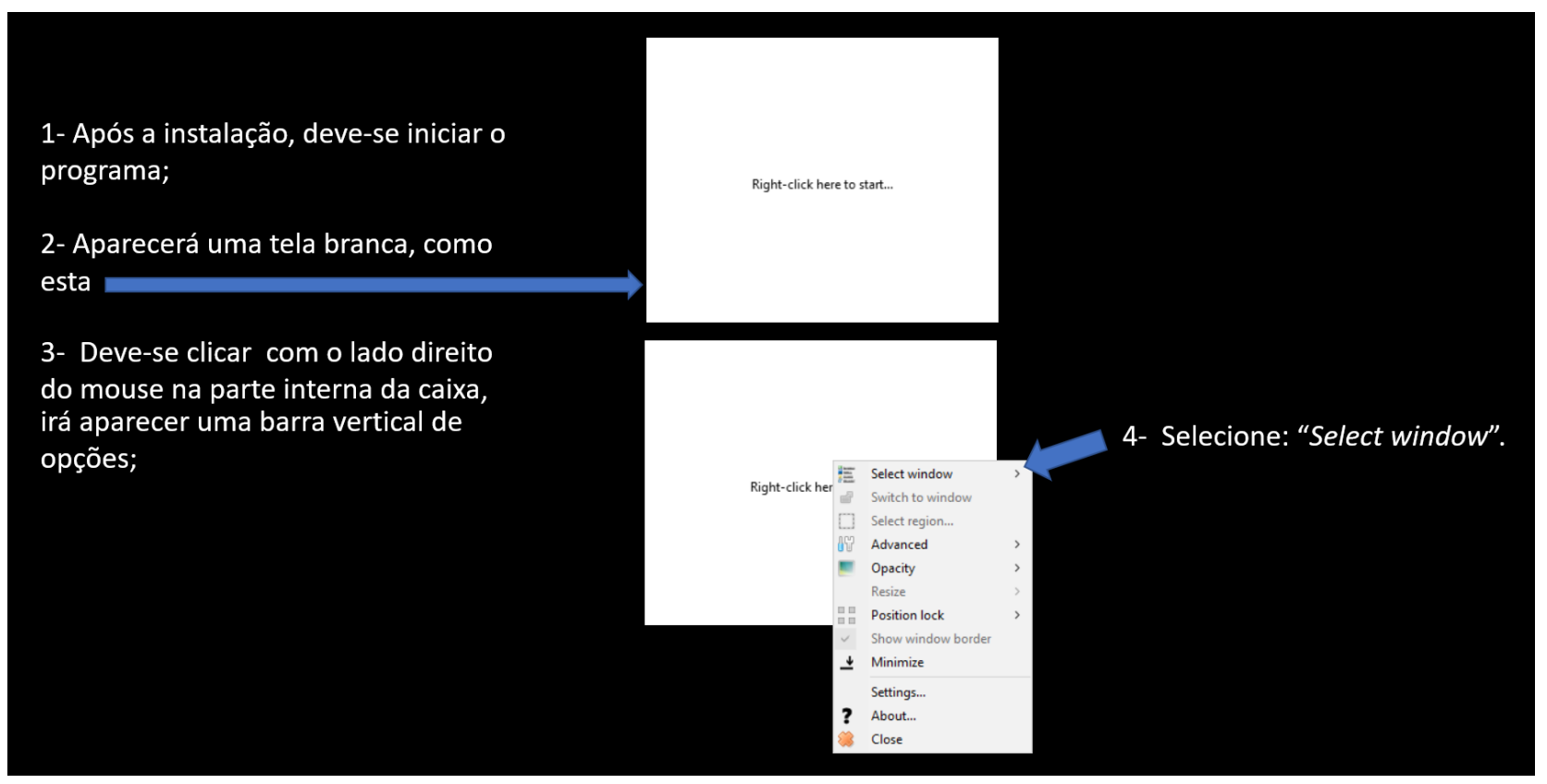

Fonte: Autoria própria. 
Figura 7: Parte dois do tutorial de uso do "OnTopReplica".

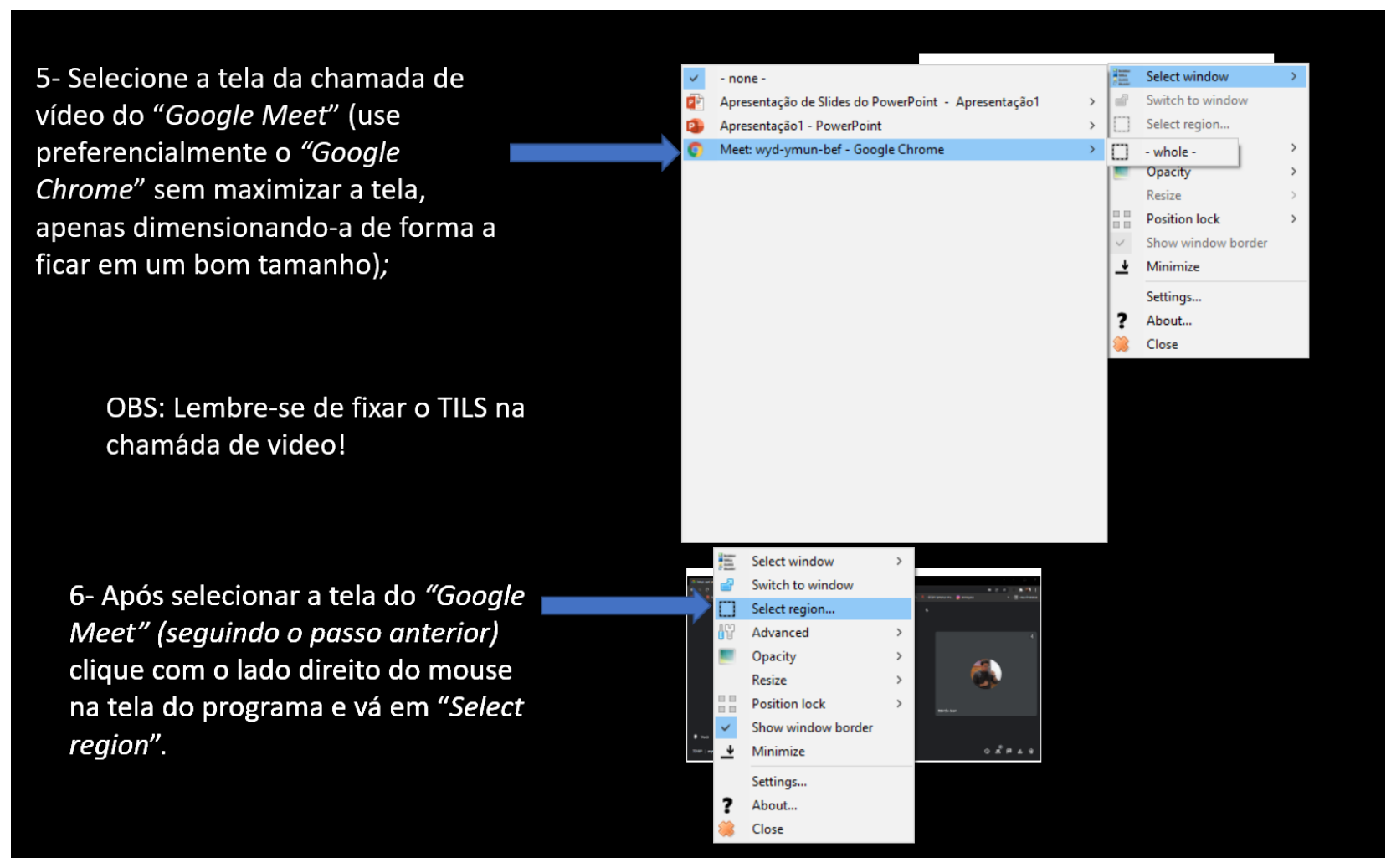

Fonte: Autoria própria.

Figura 8: Parte três do tutorial de uso do "OnTopReplica".

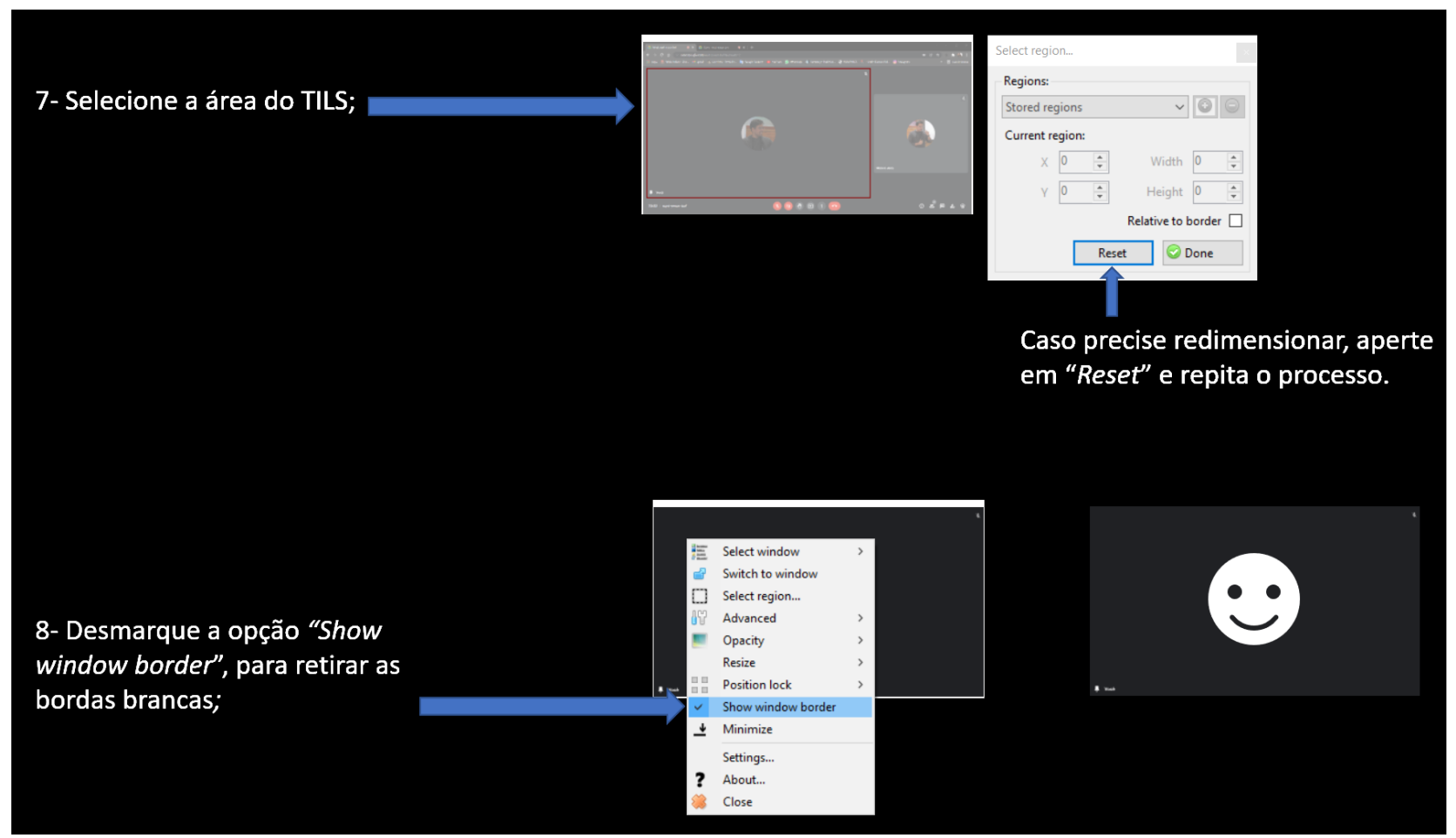

Fonte: Autoria própria. 
Figura 9: Parte quatro do tutorial de uso do "OnTopReplica".

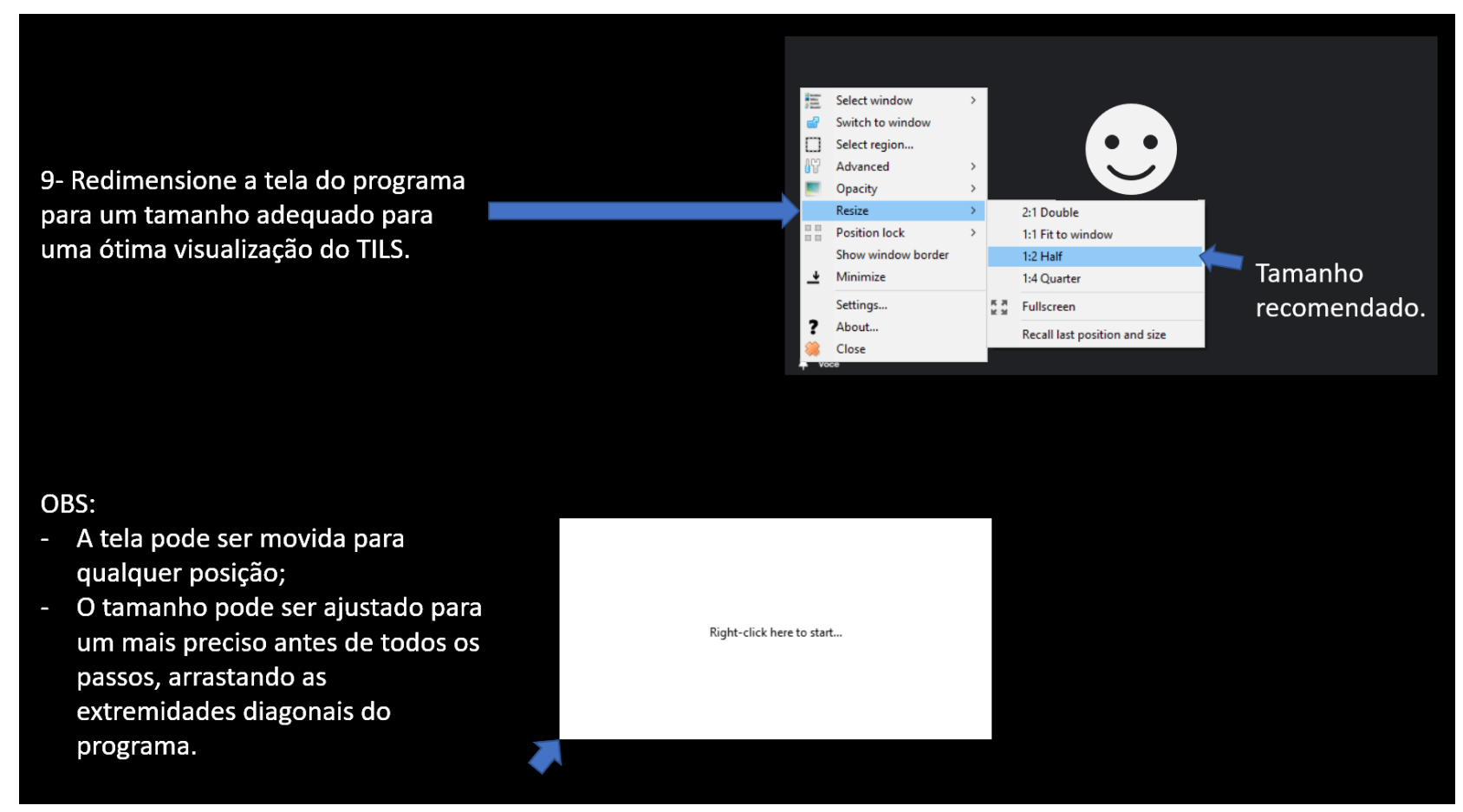

Fonte: Autoria própria.

Como averiguado no tutorial de uso nas Figuras 6 a 9, o software é passível de ser utilizado, facilitando a construção de um ambiente inclusivo de aprendizado e reduzindo (ou anulando) o sentimento de exclusão gerado quando os surdos são segregados da participação no processo de ensino e aprendizagem. O professor juntamente com a equipe pedagógica tem a função de ultrapassar as barreiras da segregação, tornando o ambiente propício para a participação efetiva dos discentes surdos, ansiando numa sólida construção do conhecimento no ambiente escolar.

$3^{\circ}$ Momento - Aplicação da solução por intermédio de uma aula inclusiva e captação do feedback do discente surdo e dos TILS.

No terceiro momento ocorreu a aula teste para validação do discente surdo para com a metodologia criada. Durante todo o processo de aplicação, o discente mostrou-se participativo e interessado pelo conteúdo apresentado, muito disso se deve além dos Recursos Visuais utilizados, ao TILS, que realizou a adaptação objetivando facilitar o entendimento do discente surdo, tal ação foi possível porque o intérprete teve acesso ao material durante todo procedimento de construção, dando suas opiniões, no intuito de suprir as necessidades visuais do surdo.

A Figura 10 apresenta o conjunto completo da metodologia, RV sem poluição visual, com cor neutra de fundo que ressalta os recursos presentes nas TDICs com imagens de qualidade, destaques para pontos específicos, com espaço reservado para janela do TILS, em um tamanho adequado para uma perfeita visualização da sinalização em LIBRAS. 
Figura 10: RV com o uso do "OnTopReplica".

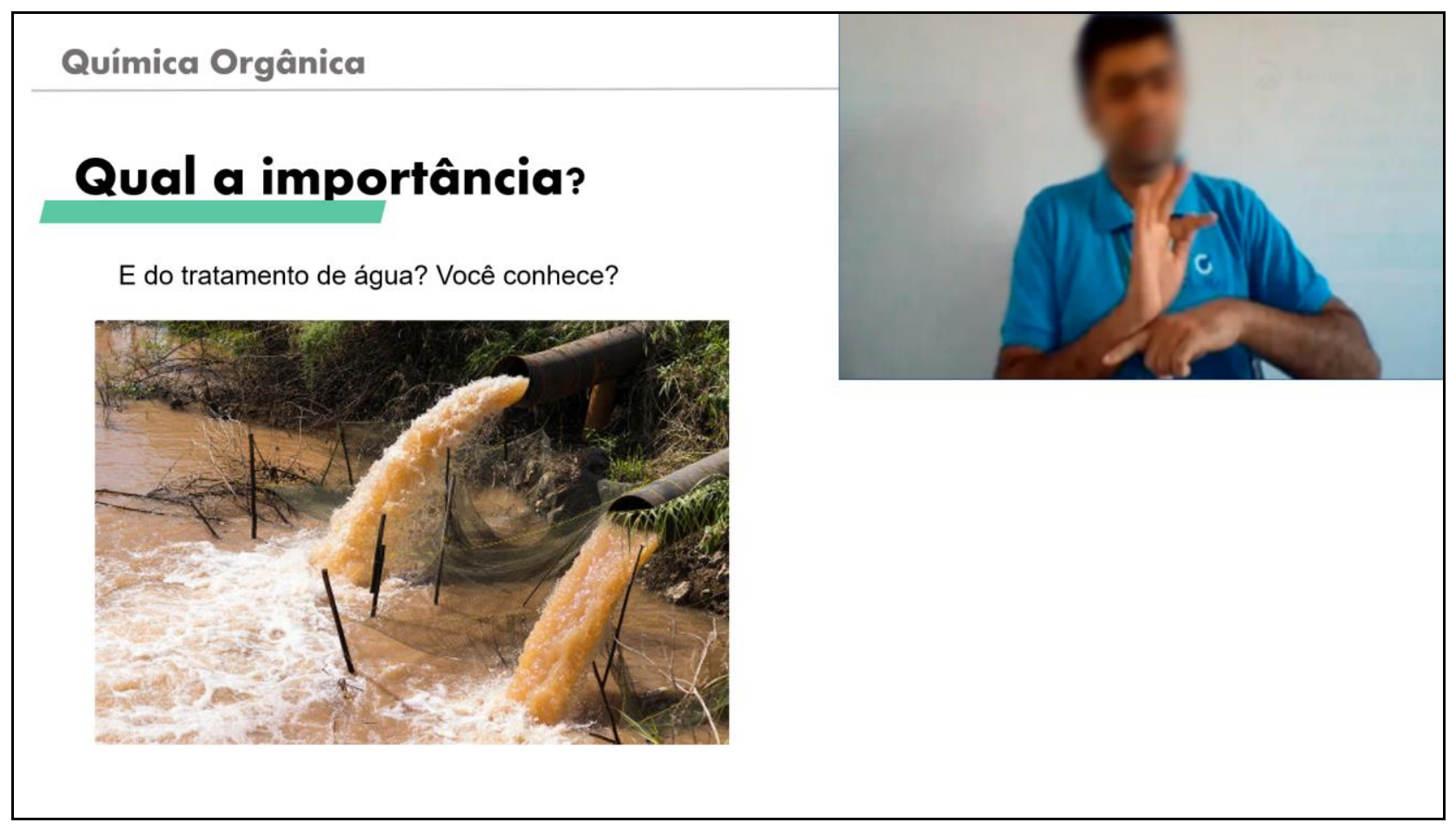

Fonte: Autoria própria.

Ao fim da aplicação o discente surdo expressou que havia gostado da metodologia utilizada, o que valida a reprodução de trabalhos, projetos e ações, amparados neste trabalho, que tem como propósito principal, além de demonstrar a efetividade da metodologia inovadora, explorar a visualidade dos surdos, atentando-se que o uso de imagens, especialmente na substituição de elementos textuais, associado a um "design" limpo do RV, "comprovadamente contribui com o processo de ensino e aprendizagem do aluno surdo, devido ao potencial do sentido visual” (Sofiato, 2016, p. 789).

Para Campello (2008), a aplicabilidade da abordagem visual inclusiva é denominada de Pedagogia Visual (PV), sendo um dos pilares da educação de surdos (juntamente com o TILS, que é a peça fundamental), uma vez que se ampara nas experiências visuais e entendimentos próprios da comunidade surda, atuando como uma emancipação cultural e pedagógica (Perlin, 2006).

Segundo Gomes e Souza (2020), a valorização da visualidade aliada à busca de novas formas de apresentar os conteúdos trabalhados, corrobora com a construção do conhecimento para o discente surdo. Atentando-se ao cenário escolar, constatou-se que é de fundamental importância para uma verdadeira inclusão do discente surdo, a existência de uma ação conjunta entre o professor e o TILS, para que o processo de aprendizagem possa ocorrer de forma enaltecedora.

\section{Conclusão}

O presente trabalho aponta que o processo de inclusão é crucial dentro do ambiente escolar, pois promove a participação ativa dos discentes surdos, auxiliando-os na construção do saber efetivo, minimizando o estigma de marginalização e segregação.

O método de ensino demonstrado apresentou-se inovador, para todos os envolvidos nesta pesquisa. Os problemas encontrados no início da aplicação mostraram-se apenas um obstáculo inicial, visto que, com a utilização correta das TDICs e dos RV, as barreiras educacionais encontradas no processo de inclusão foram ultrapassadas, favorecendo o processo de ensino e aprendizagem de maneira significativa. 
Destarte, almejando o processo inclusivo de qualidade, faz-se necessário uma urgente modificação na metodologia utilizada no Ensino Remoto Emergencial, sendo de fundamental importância, uma abordagem mais voltada para o perfil dos alunos surdos. Portanto, verificou-se que a utilização da metodologia inovadora desenvolvida, como o amparo das TDICs, fornece aos educandos a oportunidade de aprendizado.

Diante dos resultados obtidos nesta pesquisa, nota-se a necessidade de uma maior exposição/acesso a recursos tecnológicos para inclusão dentro da sala de aula, facilitando o processo de ensino e aprendizagem discente. Sendo assim, esta pesquisa visou contribuir para a facilitação do processo educativo inclusivo de discentes surdos e para a divulgação de recursos tecnológicos disponíveis para esse procedimento. A educação é uma ferramenta para a cidadania, e se baseada no potencial humano, a construção coletiva emergirá justamente pela diversidade do ser e da multiplicidade do saber de cada pessoa com ou sem diferenciação sensorial e de aprendizagem presente na sala de aula.

\section{Referências}

Amaral, L. M. M. (2020). Buscas por Notícias Durante a Pandemia de Covid-19: Uma abordagem infodemiológica a partir de dados do Google Trends.

Bailenson, J. N. (2021). Nonverbal Overload: A Theoretical Argument for the Causes of Zoom Fatigue. Technology, Mind, and Behavior, 2(1). https://doi.org/10.1037/tmb0000030.

Brasil. (2015). Lei no 13.146 de 6 julho de 2015. Institui a Lei Brasileira de Inclusão da Pessoa com Deficiência (Estatuto da Pessoa com Deficiência). Diário Oficial da União, Brasília, 07de julho de 2015. Seção 1, p.2-11. Brasília.

Brasil. (1994). Declaração de Salamanca e linha de ação sobre necessidades educativas especiais. Brasília: Corde.

Brasil. (1996). Lei $n^{\circ}$ 9.394, de 20 de dezembro de 1996. Estabelece as diretrizes e bases da educação nacional.

Brasil. (2020). Todos Pela Educação. Ensino a distância na Educação Básica frente à pandemia da Covid-19. Nota Técnica.

Campello, A. R. et al. (2008). Pedagogia Visual na Educação Dos Surdos-Mudos. 2008. Tese (Doutorado) - Universidade Federal de Santa Catarina.

Coqueiro, N. P. S. \& Sousa, E. C. (2021). A educação a distância (EAD) e o ensino remoto emergencial (ERE) em tempos de Pandemia da Covid 19. Brazilian Journal of Development, 7(7), 66061-66075.

Ferreira, L. G., Ferraz, R. D. \& Ferraz, R. D. C. S. N. (2021). Trabalho docente na pandemia: discursos de professores sobre o ofício. fólio-Revista de Letras, 13(1).

Gabardo, P., Quevedo, S. R., \& Ulbricht, V. R. (2010). Estudo comparativo das plataformas de ensino-aprendizagem. Encontros Bibli: revista eletrônica de biblioteconomia e ciência da informação, 65-84.

Gomes, E. M. L. S. \& Souza, F. F. (2020). Pedagogia visual na educação de surdos: análise dos recursos visuais inseridos em um LDA. Revista Docência e Cibercultura, 4(1), 99-120.

Glat, R, Ferreira, J. R, Oliveira, E. da S. G. \& Senna, L. A. G. (2003). Panorama Nacional da Educação Inclusiva no Brasil. Relatório de consultoria técnica, Banco Mundial.

IsFlocos. (2017). Por que queremos escola bilíngue para surdos? Youtube. https://youtu.be/qZMu6RG-EDM.

Kubrusly, M., Coelho, R. A., Augusto, K. L., Peixoto Junior, A. A., Santos, D. C. de O., \& Oliveira, C. M. C. de. (2021). Faculties' perception about ProblemBased Learning in remote education during pandemic COVID-19. Research, Society and Development, 10(5), e53510515280. https://doi.org/10.33448/rsdv10i5.15280.

Maciel-Ferreira, T. (2021). As Metodologias Ativas na comunicação com aluno surdo: avaliação de uma Experiência de Investigação-Ação. Rev. Int. Investig. Cienc. Soc, 24-51.

Marconi, M. de A.; \& Lakatos, E. M. (2021). Fundamentos de Metodologia Cientifica. (9a ed.), Atlas.

Mendes, L. C., \& dos Reis, D. A. (2021). Políticas públicas de educação inclusiva no Brasil e na Bahia: avanços e recuos. Research, Society and Development, 10(3), e5110312989-e5110312989.

Oliveira, P. D. J. D., Pinto de Oliveira, W., \& Costa, R. P. (2021). A percepção dos professores sobre a inclusão no ensino remoto dos alunos com deficiência durante a pandemia do novo coronavírus. Research, Society and Development, 10(7), e4710716380-e4710716380.

Ontopreplica. (2017). Versão 3.5.1.0.: Lorenz Klopfenstein.

Pereira, A. T. C., Schmitt, V., \& Dias, M. R. A. C. (2007). Ambientes virtuais de aprendizagem. AVA-Ambientes Virtuais de Aprendizagem em Diferentes Contextos. Rio de Janeiro: Editora Ciência Moderna Ltda, 4-22.

Perlin, G.; \& Strobel, K. (2006). Fundamentos da educação de surdos. Florianópolis: UFSC. http://www.drb-m.org/av1/fundamentoseeducacao desurdos.pdf. 
Research, Society and Development, v. 11, n. 2, e15911225521, 2022

(CC BY 4.0) | ISSN 2525-3409 | DOI: http://dx.doi.org/10.33448/rsd-v11i2.25521

Quadros, R. M. de. (1997). Educação de surdos- A aquisição da linguagem. Artmed.

Rump, J. \& Brandt, M. (2020). Zoom fatigue. Institut für Beschäftigung und Employability. https://www.ibeludwigshafen.de/wpcontent/uploads/2020/09/E N_IBE-Studie-Zoom-Fatigue.pdf.

Sassaki, R. K. (2004). Pessoas com deficiência e os desafios da inclusão. Revista Nacional de Reabilitação, 30(09).

Silva, I. R., Freitas, T. N., de Araújo, N. F. M., da Silva Sousa, D. L., de Araújo Júnior, M. A., Medeiros, A. M., \& Silva, R. S. (2021). Acessibilidade digital em tempos de ensino remoto. Research, Society and Development, 10(4), e60010414966-e60010414966.

Sousa, R. C. (2020). Vulnerabilidade, vida precária e luto: os impactos da pandemia da Covid-19 no Brasil. Unifesspa: Painel Reflexão em tempos de crise, 25 .

Sofiato, C. G. (2016). Ontem e hoje: o uso de imagens na educação de surdos. Journal of Research in Special Educational Needs, 16, 789-794. https://nasenjournals.onlinelibrary.wiley.com/doi/epdf/10.1111/1471-3802.12217.

Strobel, K. (2008). As Imagens do outro sobre a cultura surda/ Karin Strobel. Ed. da UFSC, 118p: il.

Trevisan, S. F. (2019). ENEM em libras e a avaliação na educação básica pelo olhar dos surdos. Trabalho de Conclusão de Curso. UFSCAR. https://repositorio.ufscar.br/handle/ufscar/12897

Vieira, C. R., \& Molina, K. S. M. (2018). Pedagogical practice in deaf education: the intertwining of different approaches in the educational context. Educação e Pesquisa, 44.

ViSurdo. (2018). Escola bilíngue ou inclusiva para os surdos? Youtube. https://youtu.be/MQPi6IYT-x0.

Weller, W.; \& Pfaff, N. (2011) Pesquisa Qualitativa em Educação: Origens e Desenvolvimentos. In: Weller, Wivian; Pfaff, Nicolle (orgs.). Metodologias da pesquisa qualitativa em educação. Vozes. 